\title{
El manejo territorial de los camélidos en la circumpuna de Atacama desde el Arcaico al Formativo (10.000-2400 aP): Una aproximación isotópica y taxonómica - Erratum
}

\author{
Patricio López Mendoza, Celeste Samec, Lautaro Núñez, Carlos Carrasco, Rodrigo Loyola \\ e Isabel Cartajena
}

DOI:10.1017/laq.2021.66. Published online by Cambridge University Press, September 21, 2021

$\mathrm{I}$

$\mathrm{n}$ the original publication of this article (López Mendoza et al. 2021) the first affiliation of author Celeste Samec was incorrectly stated. The article has since been corrected.

\section{Reference Cited}

López Mendoza, Patricio, Celeste Samec, Lautaro Núñez, Carlos Carrasco, Rodrigo Loyola e Isabel Cartajena 2021 El manejo territorial de los camélidos en la circumpuna de Atacama desde el Arcaico al Formativo (10.000-2400 aP): Una aproximación isotópica y taxonómica. Latin American Antiquity 33:575-595. DOI:10.1017/laq.2021.66. 